\title{
Problems of Injury Surveillance and Documentation in Cricket: Indian Experience
}

\author{
${ }^{1}$ Mandeep Dhillon, ${ }^{2}$ Bhavuk Garg, ${ }^{3}$ Sidak Dhillon, ${ }^{4}$ Sharad Prabhakar
}

\begin{abstract}
Cricket is the most prevalent and popular sport in India. Its expansion, including recent inclusion of T20 format over the last decade, has placed greater demands on cricketers and led to an increased incidence of injuries worldwide. Worldwide, in all forms of sport, successful injury prevention requires ongoing injury surveillance as a fundamental process. Unfortunately, injury surveillance is not the norm in Indian sports. We do not have any specific documentation protocol for documenting injury patterns, causative mechanisms, and analyzing the incidence of different cricket-related injuries in players of different ages except the Aclass test players. Despite being the most popular team sport in India, there is just a single publication in the medical literature reporting cricket injuries from India. This article reviews the burden of cricket injuries in both national and international perspective and emphasizes the potential and need of an injury surveillance program to improve cricket sport in India.
\end{abstract}

Keywords: Cricket, Injury, Surviellance.

How to cite this article: Dhillon M, Garg B, Dhillon S, Prabhakar S. Problems of Injury Surveillance and Documentation in Cricket: Indian Experience. J Postgrad Med Edu Res 2016;50(3):148-150.

Source of support: Nil

Conflict of interest: None

\section{INTRODUCTION}

Cricket is one of the world's major team sports, with a passionate following in the subcontinent. Since 1983, cricket has become the most popular sport in India and is gaining in importance in all South-East Asian countries. ${ }^{1}$ Recent increase in playing hours and increased performance expectations has led to greater demands on cricketers. ${ }^{2}$ Recent inclusion of limited-over cricket (like T-20 games) has put a greater demand on cricketers due to an exponential increase in number of matches as well as number

\footnotetext{
${ }^{1}$ Professor, ${ }^{2,4}$ Assistant Professor, ${ }^{3}$ Resident

${ }^{1,4}$ Department of Orthopaedics, Postgraduate Institute of Medical Education and Research, Chandigarh, India

${ }^{2}$ Department of Orthopaedics, All India Institute of Medical Sciences, Delhi, India

${ }^{3}$ Department of Orthopaedics, Government Medical College and Hospital, Chandigarh, India
}

Corresponding Author: Bhavuk Garg, Assistant Professor Department of Orthopaedics, All India Institute of Medical Sciences Delhi, India, Phone: +919899558021, e-mail: drbhavukgarg@ gmail.com of hours played. This increased demand has further led to an increased incidence of injuries worldwide.

However, despite being the most popular team sport in India, there is just a single publication in the medical literature reporting cricket injuries from India, which was published by us in 2012. ${ }^{1}$ Most of the previously published epidemiological studies on cricket injuries have come from South Africa, Australia, and England, particularly at the elite level. ${ }^{3-6}$

\section{BURDEN OF CRICKET INJURIES}

Although cricket is a non-contact sport, various acute injuries at different anatomical sites have nevertheless been reported. These include injuries to the head, neck and face (20-25\%), traumatic eye injuries (5.4-9\%), injuries to the upper limb (25-32\%), back and trunk injuries (14-18\%), as well as lower limb injuries (25-30\%) and are perhaps the commonest of all injuries sustained by cricketers. The injuries sustained by different specialists of the game, namely bowlers, batsmen, and fielders have also been investigated. Among all of these, major cause of injuries remains in the bowling. Fast bowlers are most prone to injury, with back injuries, predominantly lower back, having been discussed and reported the most often. As published previously, Australian fast bowlers have fairly common occurrence of spondylolysis of the lumbar vertebrae. ${ }^{3}$ Other common injuries in bowlers include abdominal muscle tears, shoulder injuries, patellar tendonitis, bruised heels, and shin splints. The most frequent injuries while batting ${ }^{4}$ include muscle strains and impact injuries, and a spectrum of impact injuries to the head, eye injuries (like retinal detachment and rupture of the Globe), fractures of the distal third of the ulna, ribs and phalanges, soft-tissue injuries to the upper leg, abdomen, and testicles. ${ }^{5-7}$ Fielders are particularly susceptible to shoulder injuries.

Stretch $^{7}$ also postulated several factors for injuries during cricket matches. These factors include:

- Sudden increase in the length of bowling spell(s) during a match, as opposed to the amount of bowling usually performed in the nets

- Attempts to bowl too fast

- Captain over-bowling a bowler who is performing well

- Bowler coming for subsequent bowling spells, usually without sufficient recovery from a previous bowling spell 
- Sudden increase in the number of matches played

- Inadequate warming up before bowling, batting, and fielding

- Return to match play too soon after an injury.

Despite the significant incidence of injuries in professional and semi-professional cricketers, very few studies focused on documenting the incidence and publishing worldwide. A survey conducted by the British Sports Council $^{6}$ reported 2.6 injuries per 10,000 hours played. A similar survey conducted by the Australian Cricket Board $^{3}$ reported the figure to be 24.2 per 10,000 player hours, much higher than the injuries reported by the British Council. In our study, ${ }^{1}$ where we focused only on upper limb injuries, we noted an incidence of 1.24 per 10,000 hours of play, which is much less incidence as compared to other studies. ${ }^{3-8}$ After data analysis from other studies, we observed that they had calculated their injury incidence based on the injuries sustained during matches and involved an elite international-level cohort. Ours was a different methodology, as our calculations were based mainly upon injuries sustained during practice and involved a larger number of younger players (under 19 and under 17); the total number of playing hours also included the time spent in physical training, which was not factored in the other studies. ${ }^{1}$

Some aspects of playing cricket were noted to be unique to India; we found that most of our players continued to practice or play cricket during the so-called "off season" (summer months) also; thus, the total playing time becomes much more in these circumstances, during one calendar year. We also suggested that international players anyway play more intense matches, with more competitive strains, and this may be one of the reasons for higher injury rate in the international studies. ${ }^{1}$

\section{INTERNATIONAL INJURY SURVEILLANCE AND DOCUMENTATION OF CRICKET INJURIES}

The documentation of cricket injuries can be traced back to 1751, when a cricket ball killed the Prince of Wales, striking him in the head. ${ }^{9}$ Although literature on cricket injuries is quite limited, these injuries are now commonly seen, with a significant occurrence in fast bowlers. The unfortunate aspect is that these may be repeat injuries, or due to an ongoing preventable process, and it is in this area that surveillance, documentation, strategies, and education play a dominant role. ${ }^{10}$ Worldwide, in all forms of sport, ongoing injury surveillance is a fundamental process behind successful injury prevention.

Various injury counter-measures to prevent or reduce the risk of injury have been designed as a result of diligent injury surveillance. These measures are either specific to the sport (e.g., improved skills and techniques to prevent overuse injuries and protective equipment to prevent impact injuries) or more generic (e.g., physical preparation, environmental conditions, modified rules, education, coaching, first aid, and appropriate rehabilitation to reduce recurrence of an injury). ${ }^{2}$

Many times, successful injury surveillance in sports has proven elusive (even in better established international sports), partially due to absence of welldefined and consistent injury definitions related to that particular sport. This often makes comparison of injury rates between different levels of players, or even firstclass players of different countries quite difficult. The group headed by John Orchard has rectified this to some extent in the advanced nations. Various terms like injury incidence and injury prevalence are commonly used for injury surveillance.

Injury surveillance in cricket usually focuses on "match time-loss injuries only" rather than "all reported" injuries, which is usually the case in football and rugby injuries reporting. Limited resources for injury surveillance are one of the main reasons that most of the cricket-related data focuses on match time-loss injuries. It is easy to comply if we have fewer reporting requirements. ${ }^{11,12}$

\section{BENEFITS OF INJURY SURVEILLANCE}

Various International Cricket bodies, like Australian Cricket Board, publish detailed data regarding various injury patterns among all levels of players yearly, allowing an authentic documentation of injuries and giving an idea of the epidemiology and the expected outcome. Preventive measures in the form of player protection and advice can thus be incorporated easily and scientifically. This surveillance will also help us to focus on various injury patterns as well the education of cricket players regarding preventive measures, including changes in playing methods.

\section{CRICKET INJURY SURVEILLANCE IN INDIA}

Unfortunately, injury surveillance is not the norm in Indian sports except at the international level. ${ }^{13}$ Also, being considered a non-contact sport, authorities often have less serious attitude toward injuries in cricket and often documentation, prevention strategies are ignored, despite the money, i.e., being poured into the sport. Overuse injury has become quite common in today's world, mostly seen in the shoulder and wrist in spinners, shoulder and back of fast bowlers, and even sometimes in the ankle ${ }^{14}$ and elbow. In our country, however, there is no specific documentation protocol focused on documenting injury patterns, identifying mechanisms, and calculating the injury incidence in cricketers at various ages, except the test-playing A-class players. ${ }^{15}$ 


\section{OBSTACLES IN INDIA}

Problems unique to India are lack of organized sports methodology at any level, limited availability of trained sports physicians/physiotherapists at various centers, minimal medical support at the junior cricketer level where formative patterns of the game are evolving, paucity of documentation at all levels below Ranji Trophy players, lack of records of previous injury, and inadequate rehabilitation after injury. Screening programs are nonexistent at many levels of the game. A study conducted in cricketers of a state team revealed lack of knowledge, poor documentation, and players hiding some injuries to stay in the team, which has serious long-term repercussions. ${ }^{15}$ The knowledge gained from the experience in India is emphasized by the West Indian experience, where significant reduction in injury rates has come about due to a properly implemented surveillance and documentation program.

\section{HOW TO IMPROVE INJURY SURVEILLANCE AND DOCUMENTATION IN INDIA}

Injury and illness surveillance can be considered a vital first step in the management and prevention of athlete health problems. Sporting organizations can use effective collection, reporting of different injury patterns, impact on illness types, rates, severity causes as well as their analysis to identify those risk factors which have the biggest impact on athlete health and performance. Focused efforts can then be made toward optimizing player preparation and the training and competition environment to manage injury and illness risk. ${ }^{12}$

As suggested by Orchard, ${ }^{3}$ good injury surveillance requires ongoing funding. Funding has already been reported as a crucial factor in the success or failure of national joint replacement registries. ${ }^{3}$ He also stressed upon the individual player consent for injury surveillance and recommended that it should be included in players' contracts.

Injury surveillance in cricket in India and South Asia is still in its infancy. It faces money crunch and authorities still do not recognize its importance and potential to improve Indian cricket. Publication of regular data has the potential to stimulate more funding and research efforts toward injury surveillance and pre-participation evaluation of cricketers in the whole of the subcontinent. ${ }^{1}$ This would go a long way in looking at some specialized positions unique to cricket, like wicket keeping, where many potential problems are anticipated. ${ }^{16}$

\section{REFERENCES}

1. Dhillon MS, Garg B, Soni RK, Dhillon H, Prabhakar S. Nature and incidence of upper limb injuries in professional cricket players a prospective observation. BMC Sports Sci Med Rehabil 2012;4(1):42.

2. Finch CF, Elliott BC, McGrath AC. Measures to prevent cricket injuries. Sports Med 1999 Oct;28(4):263-272.

3. Orchard J, James T, Alcott E, Carter S, Farhart P. Injuries in Australian cricket at first class level 1995/1996 to 2000/2001. Br J Sports Med 2002 Aug;36(4):270-274.

4. Stretch RA. Incidence and nature of epidemiological injuries to elite South African players. S Afr Med J 2001 Apr;91(4): 336-339.

5. Leary T, White J. Acute injury incidence in professional county club Cricket Players (1985-1995). Br J Sports Med 2000 Apr;34(2):145-147.

6. Weightman D, Browne RC. Injuries in eleven selected sports. Br J Sports Med 1975 Oct;9(3):136-141.

7. Stretch RA. The incidence and nature of injuries in club and provincial cricketers. S Afr Med J 1993 May;83(5):339-341.

8. Stretch RA. Cricket injuries: a longitudinal study of the nature of injuries to South African cricketers. Br J Sports Med 2003 Jun;37(3):250-253.

9. Brasch R. How did sports begin? Camberwell (England): Longman; 1971. p. 53-60.

10. Dhillon MS, Prasad P, Goel A, Dhillon HS. Valgus extension overload syndrome of the elbow in a test cricket fast bowler. S Afr J Sports Med 2008;20(4):119-120.

11. Orchard JW. Injury surveillance in cricket. Br J Sports Med 2013 Jul;47(10):605-606.

12. Ranson C, Hurley R, Rugless L, Mansingh A, Cole J. International cricket injury surveillance: a report of five teams competing in the ICC Cricket World Cup 2011. Br J Sports Med 2013 Jul;47(10):637-643.

13. Dhillon MS, Sandhu J, DhattSS. Editorial: a brief history of sports medicine in India. J Postgrad Med Edu Res 2013;47(2):V-VI.

14. Dhillon MS, Prabhakar S, Dhillon H, Bachal V. Foot and ankle injuries in cricket: a review. Indian J Foot Ankle Surg 2011;XXV1(2):8-12.

15. Soni RK, Dhillon MS, Aggarwal S, Dhillon H, Prabhakar S. Epidemiology of injuries in Cricketers of the Punjab Cricket Association: a prospective one year observational study. Proceedings of the 4th World Congress of Science and Medicine in Cricket, Chandigarh, India; 2011. p. 163-177.

16. Dhillon MS, Prabhakar S, Raj N. The wicketkeeper and injury. J Postgrad Med Edu Res 2013;47(2):99-102. 